Article

\title{
Sub-Hourly Variability of Stable Isotopes in Precipitation in the Marginal Zone of East Asian Monsoon
}

\author{
Tingting Han, Mingjun Zhang *, Shengjie Wang ${ }^{\circledR}$, Deye $Q u$ and Qinqin Du( \\ College of Geography and Environmental Science, Northwest Normal University, Lanzhou 730070, China; \\ 2018212292@nwnu.edu.cn (T.H.); geowang@126.com (S.W.); qudeye@nwnu.edu.cn (D.Q.); \\ geoduqin@163.com (Q.D.) \\ * Correspondence: mjzhang2004@163.com; Tel.: +86-0931-797-1750
}

Received: 8 June 2020; Accepted: 28 July 2020; Published: 29 July 2020

\begin{abstract}
Isotope data at mid-latitude locations are commonly available on annual, monthly, and daily timescales; however, they are rarely available for the variations occurring on the sub-hourly scale within individual precipitation events. To fill this gap, sub-hourly (every $10 \mathrm{~min}$ ) sequential samples were collected for nine precipitation events, and the $\delta^{18} \mathrm{O}$ values of the individual events were analyzed from June to October 2019 in Lanzhou, Northwest China. The Sequential Meteoric Water Line (SMWL) correlation between $\delta^{2} \mathrm{H}$ and $\delta^{18} \mathrm{O}$ is $\delta^{2} \mathrm{H}=7.33 \delta^{18} \mathrm{O}+9.78\left(\mathrm{R}^{2}=0.97, \mathrm{~N}=170\right)$. All events had a similar decreasing variability pattern in the initial period (before the vertical gray dotted line), while during the later period (after the vertical gray dotted line), negative $\delta^{18} \mathrm{O}$ values dominated, exhibiting a different pattern. Variations in the $\delta^{18} \mathrm{O}$ values were about $1-5 \%$ o during most intra-events. We found that $\delta^{18} \mathrm{O}$ values mainly exhibit three patterns in the intra-event, namely a "V"-shaped pattern, an " $\mathrm{L}$ "-shaped pattern, and a decreasing pattern. Positive $\delta^{18} \mathrm{O}$ values are controlled by re-evaporation in the beginning period. Relative humidity has no effect on the $\delta^{18} \mathrm{O}$ values of precipitation events, mainly because dry and warm conditions are conducive to the evaporation of rainwater in the study region. The changes in the isotopic characteristics of precipitation are closely linked to the regional climate. The continuous analysis of precipitation samples revealed that the rapid change of $\delta^{18} \mathrm{O}$ values is related to different moisture sources and transport paths. A new air mass with enriched heavy isotope intrusion can change the isotopic composition in the intra-event.
\end{abstract}

Keywords: stable isotopes; sub-hourly; sequential sampler; moisture sources; monsoon marginal zone

\section{Introduction}

Stable hydrogen and oxygen isotopes $\left(\delta^{2} \mathrm{H}\right.$ and $\delta^{18} \mathrm{O}$, respectively) are crucial components in natural water and are widely applied in ecological and hydrology research as natural tracers [1-4]. As an indispensable part of the water cycle, stable isotopes in precipitation provide abundant climate and environmental information [5,6]. Since the establishment of the global precipitation isotope network (GNIP) in 1961, its monthly and annual precipitation hydrogen and oxygen stable isotope data have attracted much attention in many relevant research fields. The data from the GNIP program have provided a further understanding of the isotopic composition in precipitation and its response to environmental change $[7,8]$. However, as the time resolution of the data is discontinuous, the mechanism of stable water isotopes during precipitation events cannot be studied in detail [9-11]. A study found that there is a significant correlation between the stable isotope composition in precipitation and the temperature, precipitation amount, elevation, and other factors-known as the environmental isotope 
effects [12]. Meanwhile, the temperature effect and the precipitation amount effect are particularly important $[12,13]$. Studies have shown that a change in moisture sources can affect the composition of stable isotopes in precipitation [14,15], and most of these studies have been based on monthly and daily timescale data for different regions $[16,17]$.

The stable isotopes of precipitation exist in each link of the water cycle and are very sensitive to environmental changes in different timescales, especially in some extreme weather events [18]. However, in different precipitation events, due to the influence of local meteorological factors, the isotope changes are intricate, and the information they provide is worth studying. Additionally, the changes in the isotopic composition of continuous precipitation are also caused by changes in moisture sources [11,19]. Most previous studies have been based on annual, monthly, and daily isotope data. However, we cannot understand the isotopic changes in detail through analyses of the data in these timescales, because the change in the physical conditions of condensation may also affect the stable isotope composition changes in the intra-event [20-22]. Some studies have been reported based on intra-event analysis. Miyake (1964) found that $\delta^{18} \mathrm{O}$ in continuous precipitation events was different in Tokyo, Japan [23]. Celle-Jeanton et al. (2004), based on 5-30 min sampling intervals, showed that the isotopic trend of intense rainfall has an " $L$ " shape and a "W" shape [20]. Munksgaard et al. (2012), through analyzing continuous precipitation in Australia, revealed the extreme variations of $\delta^{18} \mathrm{O}$ and $\delta^{2} \mathrm{H}$ [24]. $\mathrm{Xu}$ Tao et al. (2019), who sampled eight typhoons hourly in Fuzhou, found that the rain shadow effect, convection, and water vapor recycling have an influence on isotopic composition [18]. Some studies have also tried to explain the weather system, moisture transport, cloud processes, and surface meteorological conditions and found that the stable isotope changes in precipitation events were closely related to local and microphysical processes [20,22,24]. However, the sample collection for the precipitation studies mentioned above was random, i.e., collecting several samples in the precipitation process, and standardized sequential sample collection is needed for the application of automatic sampling instruments in the monsoon marginal zone of Northwest China.

In the monsoon marginal zone, the spatial and temporal distributions of precipitation are extremely uneven and have a large variability, e.g., drought and floods are frequent in summer; it is therefore an important area to reflect on for the evolution of the monsoon and its regional influence. Lanzhou City is located in the marginal zone of the East Asian monsoon, which has a relatively complex moisture source. To our knowledge, sub-hourly sequential sampling in the stable isotope composition of precipitation is rare in this region. To fill such a knowledge gap, in this study, nine events were sequentially sampled during precipitation using an Eigenbrodt sequential automated precipitation collector in Lanzhou, Northwest China, from June to October 2019. The objectives of the study were to (1) study the sub-hourly stable isotope variations in the intra-event; (2) reveal the influence of meteorological variables controlling the $\delta^{18} \mathrm{O}$ during the different periods in the intra-event; and (3) investigate the influence of moisture sources on the $\delta^{18} \mathrm{O}$ values in precipitation. The sub-hourly timescale data collected in this study can provide detailed information for the further analysis of the response of the $\delta^{18} \mathrm{O}$ values to the water cycle and climate change in the marginal zone of the East Asian monsoon.

\section{Materials and Methods}

\subsection{Site Description}

The sampling site used for this study is located in Lanzhou City $\left(35^{\circ} 34^{\prime}-37^{\circ} 07^{\prime} \mathrm{N}, 102^{\circ} 35^{\prime}-104^{\circ} 34^{\prime}\right.$ E), the capital of Gansu Province in China, which is located in the monsoon marginal area in the west of the Loess Plateau (Figure 1). In addition, it is located in the transition zone of the three climatic regions in the eastern monsoon region, the northwest arid region, and the Qinghai-Tibet Plateau region [25]. In summer, this area and the surrounding area are sensitive to moisture transport and are affected by both the monsoon and the moisture transport from the westerly zone upstream [26]. Lanzhou is a typical river valley city, with an altitude high in the west and low in the east; the Yellow 
River flows from the southwest to the northeast, passing through the whole city. The climate is of continental semi-arid type. The annual average temperature and annual average precipitation are $7.4{ }^{\circ} \mathrm{C}$ and $310 \mathrm{~mm}$, respectively. The uneven precipitation in this area is mainly concentrated from June to September, accounting for more than $60 \%$ of the annual precipitation [27].

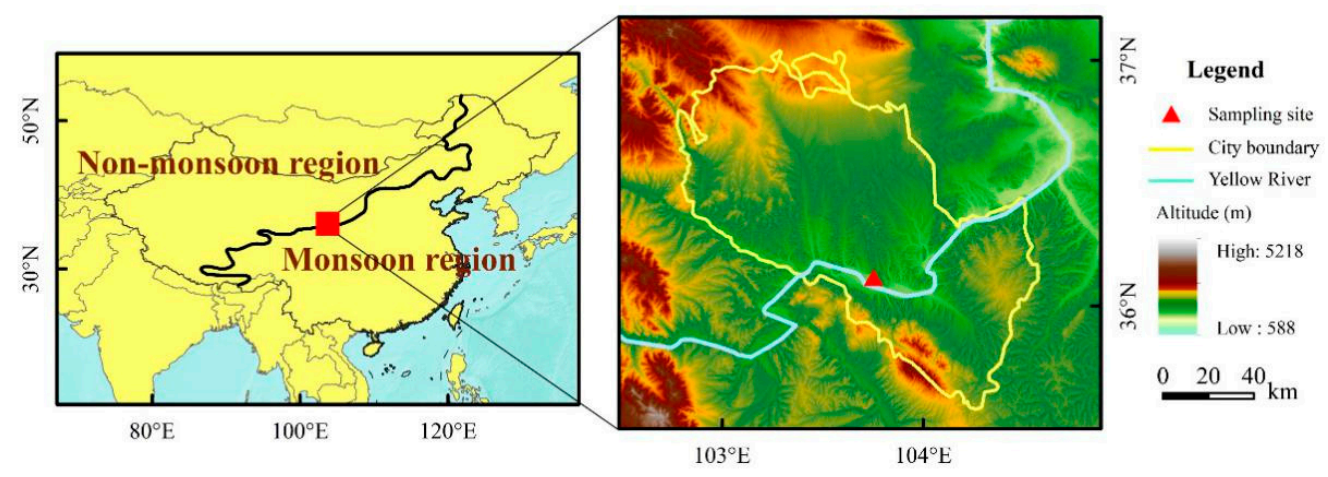

Figure 1. Map showing the location of the sampling site in Lanzhou City.

\subsection{Precipitation Sampling and Data Collection}

Each precipitation event was sampled for isotope analysis using an Eigenbrodt sequential automated precipitation collector (model NSA 181/S) produced in Germany (Figure 2), situated on the New Campus, Northwest Normal University in Lanzhou, Gansu ( $36^{\circ} 06^{\prime} \mathrm{N}, 103^{\circ} 44^{\prime}$ E) (Figure 1). The surface area of the sampler was $500 \mathrm{~cm}^{2}$. We took 170 sequential precipitation samples at intervals of $10 \mathrm{~min}$ with the automated precipitation collector during nine events from June to October 2019.

The sequential samples of individual precipitation were collected according to pre-programmed regular 10 min intervals within an event. Each event was recorded with a unique event number (E1 to E9). Sampling was triggered by a precipitation sensor, which opened the collector only when the precipitation occurred. The collector housed sixteen $1 \mathrm{~L}$ bottles (high-density polyethylene), which formed one independent cycle. Each cycle lasted $2 \mathrm{~h}$ and $40 \mathrm{~min}$ with the following settings: the first bottle collected precipitation for $10 \mathrm{~min}$ from the start of the precipitation event, with the subsequent samples collected at the same intervals. Once triggered, the rainwater flowed into a $1 \mathrm{~L}$ plastic bottle through a funnel. The sample bottle openings fitted tightly against the top plate, which prevented evaporation during the sample collection. The used bottles were soaked in deionized water for at least an hour and then air-dried prior to the sampling. To avoid isotopic fractionation, the samples were transferred immediately to $50 \mathrm{~mL}$ high-density polyethylene (HDPE) narrow-mouth bottles. They were sealed with Parafilm membrane. After each precipitation event was finished, all the collected samples will be brought back to the laboratory, refrigerated at $4{ }^{\circ} \mathrm{C}$ until the stable isotopic analysis. Meteorological variables, such as temperature, precipitation amount, and relative humidity during precipitation, were simultaneously observed every $10 \mathrm{~min}$ using an automatic weather station at the sample site. If the time between the precipitation events was less than $6 \mathrm{~h}$, it was regarded as one precipitation event; if it was longer than $6 \mathrm{~h}$, it was regarded as two precipitation events [28]. 


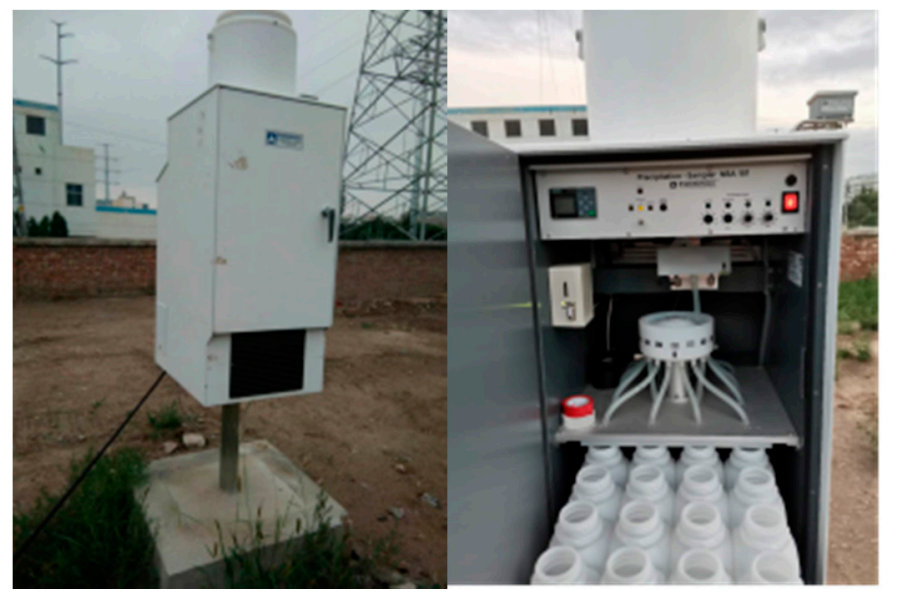

Figure 2. Photograph of the sequential automated precipitation collector.

\subsection{Stable Isotope Analysis of Precipitation}

The analysis of the precipitation samples was carried out using a liquid water isotope analyzer T-LWIA-45-EP (ABB-Los Gatos Research, CA) of the Stable Isotope Laboratory, College of Geography and Environmental Science, Northwest Normal University. According to the isotope ratio range of continuous precipitation samples, three standards were used, and the precision of $\delta^{2} \mathrm{H}$ and $\delta^{18} \mathrm{O}$ were 3e: $-79.6 \pm 0.5 \%$ o and $-11.04 \pm 0.15 \%$; $4 \mathrm{e}:-49.2 \pm 0.5 \%$ o and $-7.81 \pm 0.15 \%$; and $5 \mathrm{e}:-9.9 \pm 0.5 \%$ o and $-2.99 \pm 0.15 \%$ o, respectively [29]. Each isotopic standard and sample needed to be injected six times using a microliter syringe. To avoid the memory effect of isotope analysis, the first two injections were deleted and the average value of the next four was used for the result. The analysis results are expressed relative to Vienna Standard Mean Ocean Water (V-SMOW):

$$
\delta_{\text {sample }}=\left(\frac{R_{\text {sample }}}{R_{\text {standard }}}-1\right) \times 1000 \% \text { o }
$$

where $R_{\text {sample }}$ is the ratio of ${ }^{2} \mathrm{H} /{ }^{1} \mathrm{H}$ or ${ }^{18} \mathrm{O} /{ }^{16} \mathrm{O}$ in the samples and $R_{\text {standard }}$ is the ratio of ${ }^{2} \mathrm{H} /{ }^{1} \mathrm{H}$ or ${ }^{18} \mathrm{O} /{ }^{16} \mathrm{O}$ in the V-SMOW. The precision is $\pm 1 \%$ o for $\delta^{2} \mathrm{H}$ and $\pm 0.3 \%$ o for $\delta^{18} \mathrm{O}$.

The deuterium excess ( $d$-excess), defined as the $d$-excess $=\delta^{2} \mathrm{H}-8 \times \delta^{18} \mathrm{O}$, is considered to be another useful tracer parameter in regional precipitation studies $[7,30]$. The $d$-excess is generally controlled by evaporative conditions combining sea surface temperature, humidity, and wind speed [12,31].

\subsection{Backward Trajectory Model}

To identify the moisture trajectories of the study area, the Hybrid Single-Particle Lagrangian Integrated Trajectory (HYSPLIT) model developed by the Air Resources Laboratory, National Oceanic and Atmospheric Administration was applied. In this study, we used the meteorological dataset of the Global Data Assimilation System (GDAS) with a spatial resolution of $1^{\circ} \times 1^{\circ}$ to calculate the trajectory returned from the sampling site for one precipitation event. In the stratosphere, the average residence time of moisture is about 10 days [32,33], so the backward duration was set to 10 days. In the HYSPLIT model, the start date/time of each precipitation event needs to be set with different heights $(500,1000$, 1500,2000 , and $2500 \mathrm{~m}$ above the ground) to map the moisture trajectories. 


\section{Results}

\subsection{Stable Isotopes of Precipitation in Intra-Events}

Based on all the sequential samples, the time series of the $\delta^{18} \mathrm{O}$ values are presented in Figure 3 , and some values are reported in Table 1 . Significant variation of the $\delta^{18} \mathrm{O}$ value in the precipitation of the intra-event was observed. Within a single event, it can be seen that the initial precipitation had a heavy isotope in composition, and as the precipitation event progressed, the $\delta^{18} \mathrm{O}$ values gradually depleted with time (before the vertical gray dotted line). Additionally, the precipitation intensity (per $10 \mathrm{~min}$ ) experienced an initial increasing pattern and then a decreasing one for most of the event (Figure 3). After that, the precipitation intensity was lower than before, except for E2. During the initial decreasing period (before the vertical gray dotted line) of precipitation, the relative humidity values were low and the temperature was high, appearing as a gradual steady pattern during the later period (after the vertical gray dotted line). This may have been caused by the evaporation of low altitude clouds during the descent process [7], reflecting the progressive adiabatic condensation of vapor obeying the Rayleigh process [34]. The $\delta^{18} \mathrm{O}$ value also varied considerably during the precipitation intra-event, ranging from 1\%o to $9 \%$ o (Figure 3 and Table 1). Among the nine events, the largest difference in the range was in the $\mathrm{E} 9 \delta^{18} \mathrm{O}$ values, which ranged from $-8.6 \%$ o to $-17.4 \%$, exceeding $8.0 \%$. The E2 event showed the smallest range, which ranged from $-6.0 \%$ o to $-4.9 \%$. For all events, the difference between the highest and the lowest $\delta^{18} \mathrm{O}$ values represents the absolute change in $\delta^{18} \mathrm{O}$ during a single event at the sampling site (Table 1). In many events, however, the heavy isotope content of the precipitation increased slightly towards the end of the intra-event, reaching maximum depletion at the highest precipitation intensity (Figure 3). Therefore, the sub-cloud evaporation and the isotopic equilibrium of precipitation with ambient vapor were likely to change the $\delta^{18} \mathrm{O}$ value. The $d$-excess values of the precipitation events varied significantly during the entire period (Figure 3). During the E5 and E9 precipitation, the $d$-excess fluctuated greatly, with a range of $10.6 \%$ - $25.5 \%$, respectively, and the trend of the $d$-excess was the opposite to that of the $\delta^{18} \mathrm{O}$ values in precipitation (Figure $3 \mathrm{e}, \mathrm{i}$ ). The $d$-excess variation was less than $8.0 \%$ o for the other events. 
Table 1. Sampling information of the precipitation, and the variation of $\delta^{18} \mathrm{O}$ from the intra-events in Lanzhou.

\begin{tabular}{|c|c|c|c|c|c|c|c|c|c|c|c|}
\hline \multirow{2}{*}{ No. } & \multirow{2}{*}{ Date } & \multirow{2}{*}{$\begin{array}{l}\text { Number of } \\
\text { Samples }\end{array}$} & \multirow{2}{*}{$\begin{array}{l}\text { Isotopic } \\
\text { Pattern }\end{array}$} & \multirow{2}{*}{$\begin{array}{l}\text { Start Time } \\
\text { (hh:mm) }\end{array}$} & \multirow{2}{*}{$\begin{array}{l}\text { Rain Amount } \\
\text { (mm) }\end{array}$} & \multirow{2}{*}{$\begin{array}{l}\text { Duration } \\
\text { (min) }\end{array}$} & \multicolumn{5}{|c|}{$\delta^{18} \mathrm{O}(\% \mathrm{o})$} \\
\hline & & & & & & & Initial & Min & Max & Max-Min & Average \\
\hline E1 & 14 June 2019 & 13 & Decreasing & 15:10 & 17.50 & 130 & -0.7 & -4.1 & -0.7 & 3.4 & -3.1 \\
\hline E2 & 15 July 2019 & 11 & Stationary & 08:15 & 2.05 & 110 & -4.9 & -6.0 & -4.9 & 1.2 & -5.4 \\
\hline E3 & 19 July 2019 & 17 & V-shaped & 06:40 & 7.40 & 170 & -5.2 & -7.1 & -5.2 & 1.9 & -6.2 \\
\hline $\mathrm{E} 4$ & 21 July 2019 & 22 & others & 06:56 & 5.75 & 220 & -1.3 & -4.4 & -0.8 & 3.6 & -3.1 \\
\hline E5 & 20 August 2019 & 31 & V-shaped & 09:55 & 11.35 & 310 & -7.8 & -10.9 & -7.2 & 3.7 & -9.0 \\
\hline E6 & 30 August 2019 & 10 & V-shaped & 10:04 & 2.95 & 100 & 0.3 & -1.3 & 0.3 & 1.6 & -0.7 \\
\hline E7 & 9 September 2019 & 14 & others & 07:34 & 6.00 & 140 & -6.8 & -7.3 & -5.1 & 2.3 & -6.3 \\
\hline E8 & 12 September 2019 & 11 & Decreasing & $12: 24$ & 8.80 & 110 & -9.6 & -14.0 & -9.5 & 4.5 & -11.9 \\
\hline E9 & 15 October 2019 & 37 & L-shaped & 07:54 & 10.90 & 370 & -8.6 & -17.4 & -8.6 & 8.9 & -14.6 \\
\hline
\end{tabular}



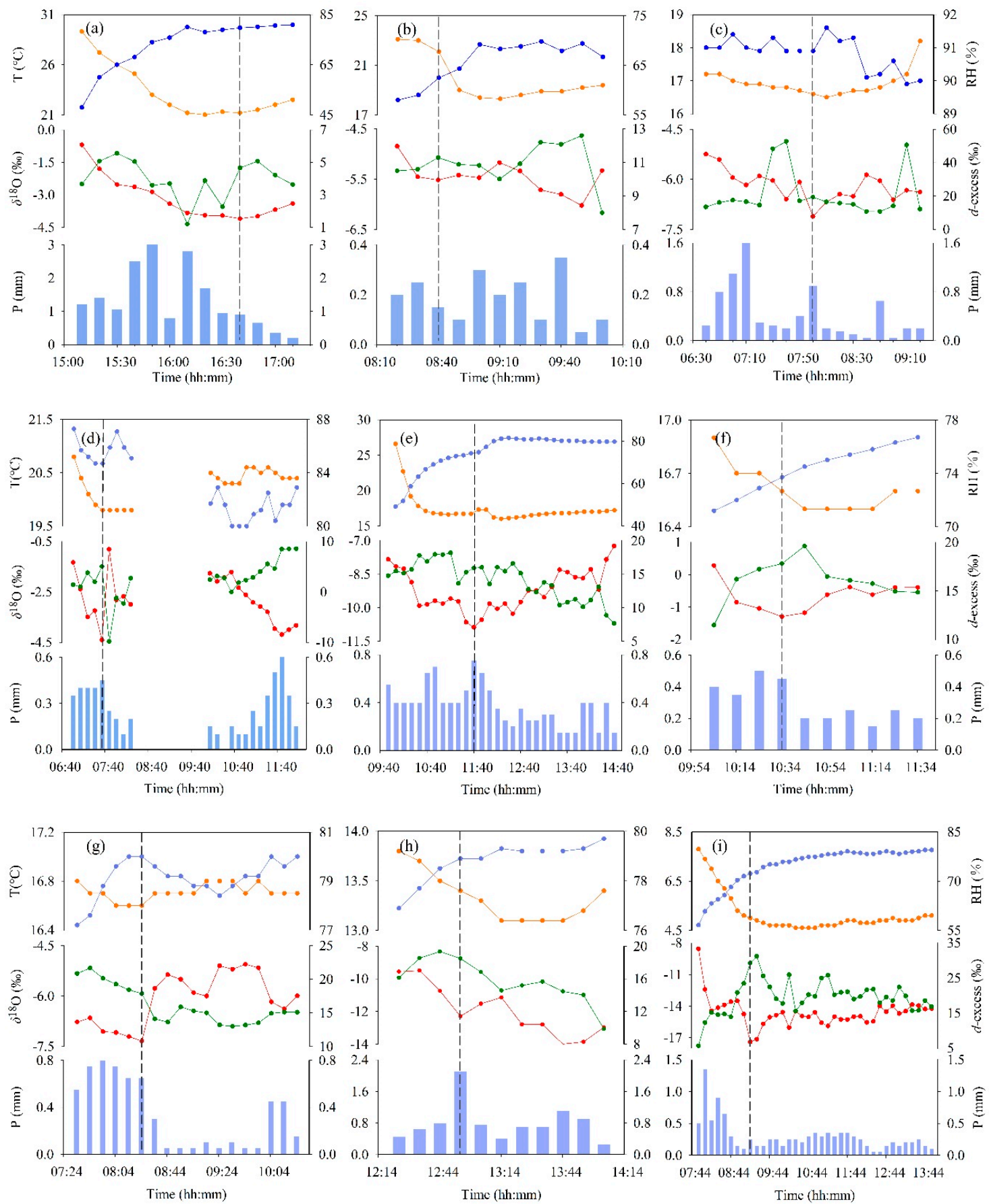

Figure 3. Characteristics of the $\delta^{18} \mathrm{O}$ values (red) of the sequentially sampled precipitation with a time series of the $d$-excess (green), air temperature ( $\mathrm{T}$, orange), relative humidity ( $\mathrm{RH}$, blue), and precipitation amount (P) for nine events at the sampling site: (a) E1; (b) E2; (c) E3; (d) E4; (e) E5; (f) E6; (g) E7; (h) E8; and (i) E9. The vertical gray dotted line divides two periods of each continuous precipitation event based on $\delta^{18} \mathrm{O}$.

\subsection{Correlation Analysis between Meteorological Variables and Stable Isotopes}

The relationship between the meteorological variables (air temperature, precipitation amount, and relative humidity) and the $\delta^{18} \mathrm{O}$ of precipitation in different periods are reported in Table 2. Whether in the entire sampling period or part of it, there was an apparently positive correlation coefficient between the $\delta^{18} \mathrm{O}$ and temperature $(p<0.001)$. The $\delta^{18} \mathrm{O}$ values of the entire sampling period had a positive correlation with temperature $(\mathrm{r}=0.84, p<0.01, n=170)$. Evaporation in the natural environment 
mainly occurs under non-equilibrium fractionation conditions. Sub-cloud evaporation occurs during the fall of the precipitation, resulting in an imbalance between the water and water vapor. With the process of continuous precipitation, stable isotopes are affected by the temperature effect. There was an apparently positive correlation coefficient between the $\delta^{18} \mathrm{O}$ and temperature. In addition, there was a negative correlation between the $\delta^{18} \mathrm{O}$ and the amount of accumulated precipitation during the entire sampling period and the later period. Consistent relationships between the $\delta^{18} \mathrm{O}$ values and the precipitation amount commonly exist in the monthly data [5,7]. However, they do not exist in the sub-hourly scale analysis in the initial decreasing period (Figure 3). This absence may be due to the complex interaction of air mass origin, trajectory, and previous precipitation history with regional factors [24], which can change rapidly with sub-hourly data and which are only revealed by this short timescale. There was almost no apparent correlation between the relative humidity and the $\delta^{18} \mathrm{O}$ value; a statistical correlation between them was shown only in the initial decreasing period. Evaporation in the natural environment mainly occurs under non-equilibrium fractionation conditions. The higher temperature and lower relative humidity $(\mathrm{RH})$ in the initial decreasing period of the precipitation imply a higher re-evaporation. Dry conditions favor rainwater evaporation in general, so the RH has little influence on the $\delta^{18} \mathrm{O}$ value of intra-events. The average relative humidity was higher during the later period. When the rain falls in a saturated environment, the water vapor rapidly condenses. The high condensation efficiency of precipitation could cause extremely negative $\delta^{18} \mathrm{O}$ values. The RH and air temperature data only reflect the local conditions at the sampling site, so the variability in these data can provide some detailed information of the change in $\delta^{18} \mathrm{O}$.

Table 2. Statistics of the correlations between the meteorological variables and $\delta^{18} \mathrm{O}$ in precipitation over short-term timescales.

\begin{tabular}{cccc}
\hline Meteorological & \multicolumn{3}{c}{$\delta^{\mathbf{1 8}} \mathbf{O}$} \\
\cline { 2 - 4 } Variables & Entire Sampling Period & Initial Decreasing Period & Later Period \\
\hline Air temperature $(\mathrm{T})$ & $0.84^{* *}(n=170)$ & $0.74^{* *}(n=62)$ & $0.89^{* *}(n=108)$ \\
Precipitation amount $(\mathrm{P})$ & $-0.31^{* *}(n=170)$ & $-0.14(n=62)$ & $-0.46^{* *}(n=108)$ \\
Relative humidity $(\mathrm{RH})$ & $-0.20(n=170)$ & $-0.30^{*}(n=62)$ & $-0.11(n=108)$ \\
\hline
\end{tabular}

* Correlation is significant at the 0.05 level (2-tailed). ${ }^{* *}$ Correlation is significant at the 0.01 level (2-tailed).

\section{Discussion}

\subsection{Correlation between $\delta^{2} H$ and $\delta^{18} \mathrm{O}$ in Precipitation}

As shown in Figure 4, the Sequential Meteoric Water Line (SMWL) of all the precipitation intra-events in Lanzhou was calculated to be $\delta^{2} \mathrm{H}=(7.33 \pm 0.07) \delta^{18} \mathrm{O}+(9.78 \pm 0.65)\left(\mathrm{R}^{2}=0.97\right.$, $p<0.01, n=170$ ). For this region, the Local Meteoric Water Line (LMWL) based on monthly $\delta^{2} \mathrm{H}$ and $\delta^{18} \mathrm{O}$ from the Global Network of Isotopes in Precipitation (GNIP) was $\delta^{2} \mathrm{H}=(6.62 \pm 0.22) \delta^{18} \mathrm{O}$ $+(-2.62 \pm 2.27)\left(R^{2}=0.99, p<0.01\right)$ [35]. Both the slope and intercept of the LMWL based on the monthly data from the GNIP are smaller than the SMWL. This is mainly due to the precipitation from the GNIP masking the post-condensation process of water vapor in the cloud at different periods after the weighted average processing, but the samples in continuous precipitation all respond to the change of water vapor condensation in the cloud, and records the fractionation rate ratio of the stable isotopes at that time. Furthermore, the slope of the SMWL is smaller than those of the Global Meteoric Water Line (GMWL: $\left.\delta^{2} \mathrm{H}=8 \delta^{18} \mathrm{O}+10\right)$ [36] and the $\operatorname{LMWL}\left(\delta^{2} \mathrm{H}=7.48 \delta^{18} \mathrm{O}+8.13\right.$ ) based on the daily precipitation date [37], which may be as a result of more intense evaporation in Lanzhou. Previous research has shown that the degree of precipitation re-evaporation is related to the relative humidity in different environments [38,39]. Before precipitation, the relative humidity is low and most values are lower than $90 \%$. Partial evaporation to some extent before precipitation always leads to heavy isotope enrichment, and isotopic non-equilibrium fractionation can lead to the relatively enriched $\delta^{18} \mathrm{O}$ values in precipitation. The $\delta^{18} \mathrm{O}$ values of the $\mathrm{E} 4$ were relatively enriched, with the 
plots distributed in the lower right of the GMWL and LMWL (Figure 4). This is mainly related to the non-equilibrium conditions that affect falling rain in a semi-arid environment, indicating that rainfall undergoes partial evaporation under warm and dry conditions, lowering the slope of the SMWL [39]. The E1 and E6 experienced recycled moisture, with the plots distributed in the upper right of the GMWL and the LMWL. The $\delta^{18} \mathrm{O}$ values of the E7, E8, and E9 were negative $(<-5 \%$ o), with the plots closely distributed to the GMWL and the LMWL (Figure 4), appearing as weak re-evaporation in the intra-event. The SMWL had a smaller slope in Lanzhou, compared with the corresponding values of the GMWL and LMWL, which was caused by the effect of re-evaporation before precipitation. Therefore, the sub-cloud evaporation and recycled moisture have an influence on the isotopic composition of continental precipitation in Northwest China; related studies have similar results [40-43]. The SMWL can more truly reflect the comprehensive environmental characteristics of the region.

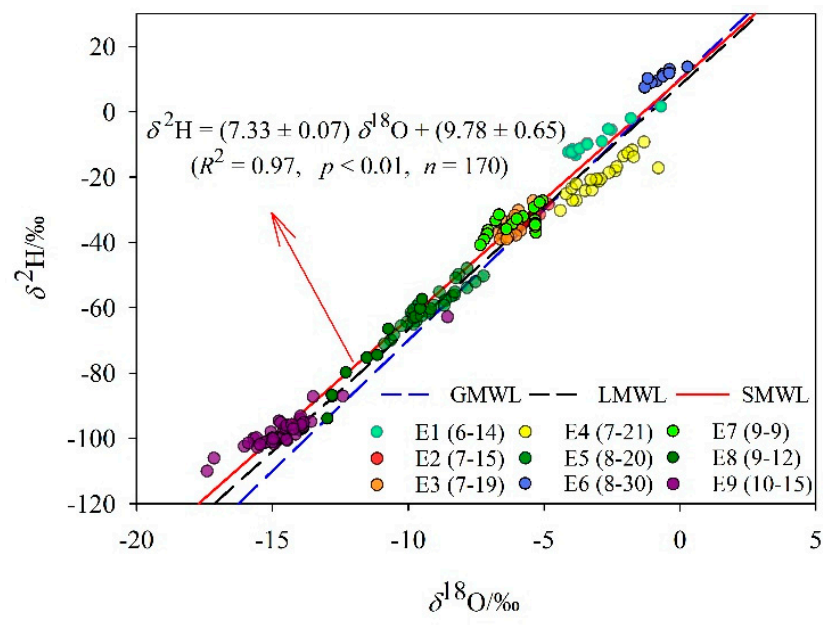

Figure 4. $\delta^{18} \mathrm{O}$ and $\delta^{2} \mathrm{H}$ relationships during the nine precipitation events from June to October 2019. E1 (14 June 2019); E2 (15 July 2019); E3 (19 July 2019); E4 (21 July 2019); E5 (20 August 2019); E6 (30 August 2019); E7 (9 September 2019); E8 (12 September 2019); E9 (15 October 2019). (SMWL: Sequential Meteoric Water Line, GMWL: Global Meteoric Water Line, LMWL: Local Meteoric Water Line $\left.\delta^{2} \mathrm{H}=7.48 \delta^{18} \mathrm{O}+8.13[37]\right)$.

\subsection{Intra-Event Characteristics of Typical Patterns}

\subsubsection{Event 5 (20 August 2019): V-Shaped Isotopic Pattern}

The V-shaped pattern shows the $\delta^{18} \mathrm{O}$ value to be generally high at the beginning, decreasing during the initial period of the event, and increasing toward the later period of the event (Figure 3). A lower $\delta^{18} \mathrm{O}$ value is generally observed when the precipitation amount is higher, e.g., in E3, E5, and E6 (Figure 3c,e,f). It is also possible for V-shaped patterns to be observed in the intra-event, e.g., during E5. With regard to variations in $\delta^{18} \mathrm{O}$ content during precipitation, the fifth event on 20 August 2019 had a significant change in $\delta^{18} \mathrm{O}$ value, and the amplitude was $3.7 \%$ o in a single event, showing a typical V-shaped pattern. In addition, its final $\delta^{18} \mathrm{O}$ value $(-7.2 \%$ o $)$ was close to the initial value $\left(-7.8 \%\right.$ o). The $\delta^{18} \mathrm{O}$ value fluctuated significantly, and multiple increase-decrease cycles occurred during the intra-event. The lowest $\delta^{18} \mathrm{O}$ value occurred at 11:40, with the maximum depletion being reached at the highest rain intensity $(0.75 \mathrm{~mm}$ during $10 \mathrm{~min})$. The temperature and relative humidity of the rainfall events recorded at the same time changed with time. In the first hour (about 11:50), the temperature dropped greatly (from $27^{\circ} \mathrm{C}$ to nearly $17^{\circ} \mathrm{C}$ ) with a decrease in the $\delta^{18} \mathrm{O}$ value. After that, during precipitation, the steady variable in temperature did not significantly influence the $\delta^{18} \mathrm{O}$ value. The $\mathrm{RH}$ was lower in the beginning and higher after 12:30, ranging from $49 \%$ to $80 \%$. 


\subsubsection{Event 9 (15 October 2019): L-Shaped Isotopic Pattern}

The L-shaped and decreasing pattern indicates that rainwater is gradually depleted in heavy isotopes during the precipitation intra-event $[29,44]$. The L-shaped pattern usually reaches a stationary value in the later period of the event [34]. Additionally, the stationary value appears during the whole event, known as a 'stationary pattern'. For example, in the ninth event on 15 October 2019, the change in the $\delta^{18} \mathrm{O}$ value appears as an L-shaped pattern (Figure 3i). The peculiarity of this $10.9 \mathrm{~mm}$ rainfall lies in its duration: 37 sequential samples collected from 07:54 to 14:04 (Table 1). The overall mean $\delta^{18} \mathrm{O}$ is $-14.6 \%$. The initial $\delta^{18} \mathrm{O}$ value of the rainwater was around $-8.6 \%$ ond dropped to $-17.4 \%$ o at 09:14. The temperature dropped from $8{ }^{\circ} \mathrm{C}$ to $4.6^{\circ} \mathrm{C}$, with a decrease in the $\delta^{18} \mathrm{O}$ value. After that, small changes in the temperature meant that it remained constant at about $4.9^{\circ} \mathrm{C}$. Furthermore, the rain intensity decreased, and the $\delta^{18} \mathrm{O}$ value remained constant with the variation being below $1 \%$ o toward the end of the precipitation. As with air temperature, the $\mathrm{RH}$ also changes during events. In general, the $\mathrm{RH}$ gradually increased from $56.6 \%$ to $79.5 \%$, remaining steady after $11: 00$. This indicates that either the physical process of controlling the stable isotopes of precipitation is stable or the height at which the rain was formed was constant [45].

\subsubsection{Event 8 (12 September 2019): Descending Isotopic Pattern}

During the event shown in Figure 3, a decreasing pattern appeared when the $\delta^{18} \mathrm{O}$ value of precipitation decreased with time, e.g., in E1 and E8 (Figure 3a,h). From the change of the $\delta^{18} \mathrm{O}$ content in the process of precipitation, the first event on the 14 June 2019 ranged from $-0.7 \%$ o to $-4.1 \%$ o. A total of $17.50 \mathrm{~mm}$ of E1 fell in $130 \mathrm{~min}$, which was collected in 13 sequential samples; the rainfall began at about 15:10. Starting from an initial $\delta^{18} \mathrm{O}$ of $-0.7 \%$, the precipitation gradually depleted in heavy isotopes, reaching $\delta^{18} \mathrm{O}$ values of $-4.1 \%$ o at $16: 40$. The temperature continued to drop from $29.5^{\circ} \mathrm{C}$ to $22.5^{\circ} \mathrm{C}$ until $13: 14$. The $\mathrm{RH}$ increased from about $48 \%$ to $80 \%$, generally maintaining an average value of $80.5 \%$. In general, with the precipitation progressing, the temperature and $\mathrm{RH}$ recorded simultaneously in the intra-events exhibited only a slight change through time and did not significantly affect the $\delta^{18} \mathrm{O}$ value. Therefore, the microphysical and local meteorological conditions in different environments have a significant influence on the isotopic composition and varies the trend of each event $[29,37]$.

\section{3. $d$-excess Contents in Precipitation Intra-Events Based on Moisture Sources}

The fluctuation of the $d$-excess in precipitation events can be attributed to the moisture source [31]. Studies have shown that the relative humidity of the atmosphere in the moisture source area increases and that the evaporative fractionation during rainfall reduces the $d$-excess in precipitation. In the initial period of E5, the highest $d$-excess was $18.2 \%$, which may reflect the rapid evaporation process of its moisture source area under unbalanced conditions. Later, the $d$-excess decreased significantly, reflecting that the relative humidity of the moisture source area increased, and the rainfall was subjected to sub-cloud secondary evaporation, leading to the $d$-excess value decreasing. For E9, during the initial period, the $d$-excess of precipitation increased rapidly, reaching $31.2 \%$ ond then showed a decreasing pattern of fluctuation. The influence of evaporation on rainfall can reduce the $d$-excess [46], and the $d$-excess increases when the atmosphere mixes with moisture from land evaporation [47]. The inverted "V"-shaped fluctuations of the $d$-excess indicate that the moisture during continuous precipitation may come from different sources.

The initial $\delta^{18} \mathrm{O}$ values of every single event can largely reflect the initial air mass or vapor from the precipitation [39]. The Lagrangian approach has been widely used to identify moisture sources in most regions [29]. Through the stable isotope and $d$-excess variations in the preceding events, it was found that during the same precipitation event there may be supplements and additional moisture from other sources that are different from the initial precipitation air mass. The moisture transport paths of E1, E5, and E9 were tracked and retrieved in the initial and the later periods. In Figure 5, it can be 
seen that the moisture at different height layers had different sources, especially at heights of 500, 1000, and $2500 \mathrm{~m}$. In E1, at 15:00 and 17:00 on 14 June 2019 (Figure 5a,b), the site was under the influence of two different precipitation sources. At heights of 500 and $2500 \mathrm{~m}$ in the early period, there was a westerly moisture transport, with longer paths and dry air masses, resulting in a larger $d$-excess (about $5.3 \%$ o), while at other layers there was vicinal continental moisture transport. The $500 \mathrm{~m}$ moisture path was shorter, and the $d$-excess in the precipitation was small (about 3.8\%o). In E5 (Figure 5c,d), the moisture came from the surrounding area of the study area in the early period at 09:00, and the local evaporation moisture may account for a large proportion of this. Later, at heights of 500 and $1000 \mathrm{~m}$, there was westerly moisture, which was consistent with the moisture source indicated by the $d$-excess in the precipitation. In E9 (Figure 5e,f), the moisture source was westerly at heights of 1000 and $2500 \mathrm{~m}$, and the other layers had continental moisture transport. With continued precipitation, the moisture path became shorter and the amount of precipitation decreased. This shows that the moisture source transport coincided with the source indicated by the $d$-excess in the precipitation. Therefore, westerlies have been shown to be the main moisture transport drivers in arid Central Asia, coincident with the research of meteorology and isotope hydrology $[1,9,48]$.
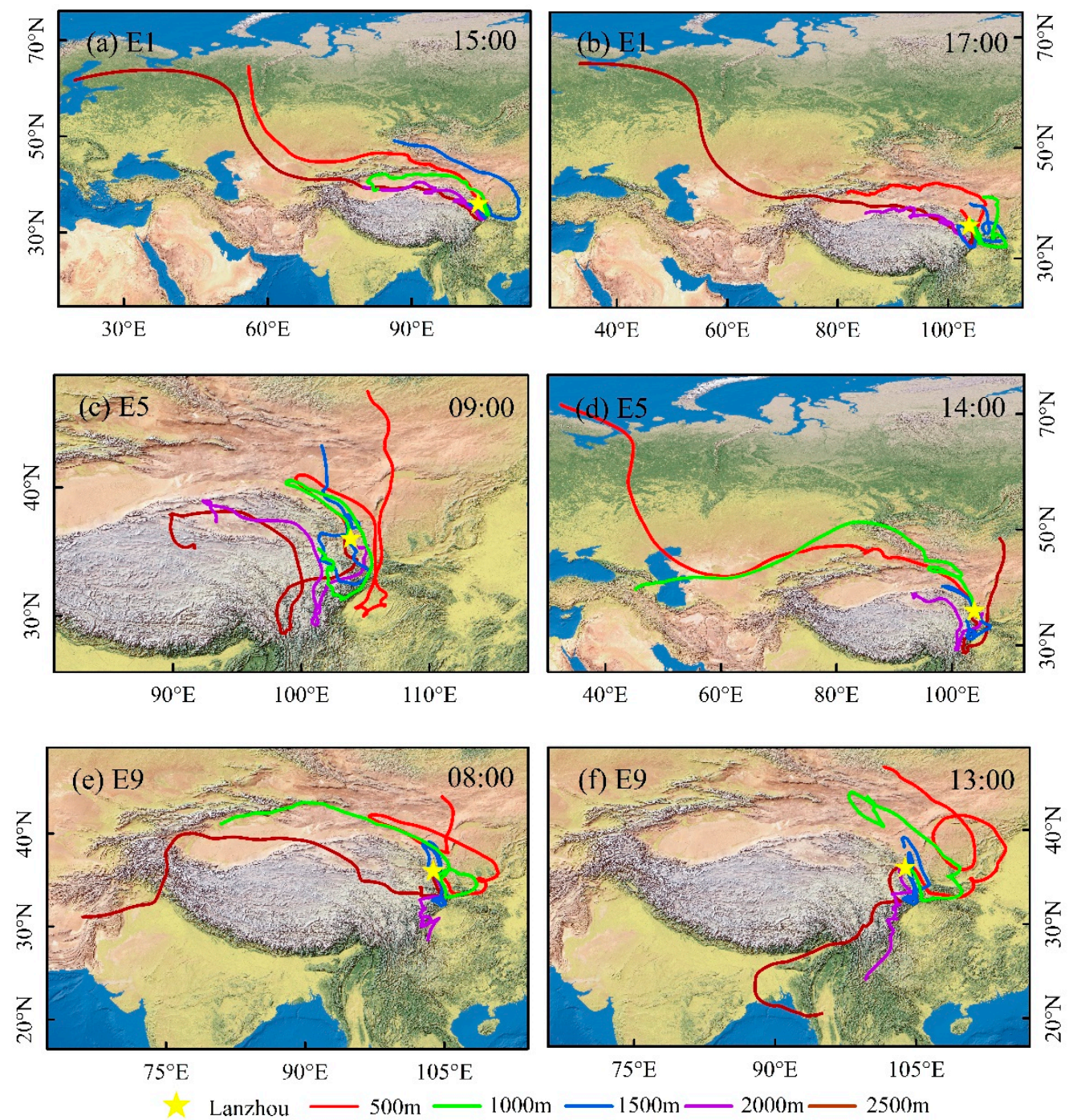

Figure 5. Moisture trajectories of the air mass for three individual precipitation events at different times during E1, E5, and E9. (a) E1, 15:00; (b) E1, 17:00; (c) E5, 09:00; (d) E5, 14:00; (e) E9, 08:00; (f) E9, 13:00. 


\section{Conclusions}

Compared with previous studies of stable isotopic composition based on annual, monthly, and daily timescale data in the monsoon marginal zone, we focused on intra-event precipitation at a mid-latitude site. Our sub-hourly resolution, single-event stable isotope data provide unique information about regional precipitation, providing valuable information for scientists for site comparisons and assessing global hydrological models. We observed the variations of sub-hourly (every $10 \mathrm{~min}$ ) stable isotope compositions $\left(\delta^{2} \mathrm{H}\right.$ and $\left.\delta^{18} \mathrm{O}\right)$ that occurred within a number of sequential precipitation samples from June to October 2019 in Lanzhou, Northwest China:

(1) The amplitude of change in the $\delta^{18} \mathrm{O}$ value of precipitation during an intra-event ranged from $1 \%$ o to $5 \%$. For all events, the difference between the highest and the lowest $\delta^{18} \mathrm{O}$ value was the absolute change in $\delta^{18} \mathrm{O}$ during a single event at the sampling site. The maximum depletion was reached at the highest amount of rain per 10 min during the intra-event, and the heavy isotope of the precipitation increased slightly toward the end of the event;

(2) The isotopic composition of precipitation was significantly influenced by the local meteorological factors. The $\delta^{18} \mathrm{O}$ in precipitation had a significant positive correlation with the temperature and a negative correlation with the precipitation amount in the sub-hourly scale during the sampling period. There was no significant correlation between $\delta^{18} \mathrm{O}$ and the precipitation amount and the relative humidity during the later period, indicating that the $\delta^{18} \mathrm{O}$ values were not governed by local meteorological factors at this time;

(3) The SMWL of precipitation is presented as $\delta^{2} \mathrm{H}=7.33 \delta^{18} \mathrm{O}+9.78\left(\mathrm{R}^{2}=0.97, \mathrm{n}=170\right)$ at the sampling site, and the slope and intercept were slightly smaller compared with the GMWL and the LMWL. This indicated that the re-evaporation of the precipitation during the initial decreasing period resulted in heavy isotope enrichment;

(4) The $\delta^{18} \mathrm{O}$ value tended to be higher when the precipitation started and toward the end of the period, with the lowest values in the middle, appearing as a "V"-shaped pattern, especially in E5. Other patterns were associated with the $\delta^{18} \mathrm{O}$ value variable in the later period of the events, as seen in E1 and E9;

(5) Different events may have very different isotopic compositions and trends at different times. Intra-event patterns are related to local, microphysical, and air mass conditions, which favor isotopic fractionation and therefore have an effect on the final isotopic composition of precipitation [32]. Therefore, the various isotopic characteristics of precipitation largely rely on the regional climate, which plays an important role in hydrology.

Author Contributions: Conceptualization, M.Z.; sample collection, T.H.; investigation, T.H.; writing-original draft preparation, T.H.; writing—review and editing, S.W., D.Q. and Q.D.; funding acquisition, M.Z. All authors have read and agreed to the published version of the manuscript.

Funding: This research was supported by the National Natural Science Foundation of China, grant number 41771035.

Conflicts of Interest: The authors declare no conflict of interest.

\section{References}

1. Tian, L.D.; Yao, T.D.; MacClune, K.; White, J.W.C.; Schilla, A.; Vaughn, B.H.; Vachon, R.; Ichiyanagi, K. Stable isotopic variations in west China: A consideration of moisture sources. J. Geophys. Res. 2007, 112, D10112. [CrossRef]

2. Yao, T.D.; Masson-Delmotte, V.; Gao, J.; Yu, W.S.; Yang, X.X.; Risi, C.; Sturm, C.; Werner, M.; Zhao, H.B.; $\mathrm{He}, \mathrm{Y}$; et al. A review of climatic controls on $\delta^{18} \mathrm{O}$ in precipitation over the Tibetan Plateau: Observations and simulations. Rev. Geophys. 2013, 51, 525-548. [CrossRef]

3. Brenčič, M.; Kononova, N.K.; Vreča, P. Relation between isotopic composition of precipitation and atmospheric circulation patterns. J. Hydrol. 2015, 529, 1422-1432. [CrossRef] 
4. Srivastava, R.; Ramesh, R.; Gandhi, N.; Jani, R.A.; Singh, A.K. Monsoon onset signal in the stable oxygen and hydrogen isotope ratios of monsoon vapor. Atmos. Environ. 2015, 108, 117-124. [CrossRef]

5. Araguás-Araguás, L.; Froehlich, K.; Rozanski, K. Deuterium and oxygen-18 isotope composition of precipitation and atmospheric moisture. Hydrol. Process. 2000, 14, 1341-1355. [CrossRef]

6. Ren, W.; Yao, T.D.; Xie, S.Y.; He, Y. Controls on the stable isotopes in precipitation and surface waters across the southeastern Tibetan Plateau. J. Hydrol. 2017, 545, 276-287. [CrossRef]

7. Gat, J.R. Oxygen and hydrogen isotopes in the hydrologic cycle. Annu. Rev. Earth Planet. Sci. 1996, 24, 225-262. [CrossRef]

8. Vuille, M.; Werner, M.; Bradley, R.S.; Keimig, F. Stable isotopes in precipitation in the Asian monsoon region. J. Geophys. Res. 2005, 110, D23108. [CrossRef]

9. Liu, J.R.; Song, X.F.; Sun, X.M.; Yuan, G.F.; Liu, X.; Wang, S.Q. Isotopic composition of precipitation over arid Northwestern China and its implications for the water vapor origin. J. Geogr. Sci. 2009, 19, 164-174. [CrossRef]

10. Li, G.; Zhang, X.P.; Wu, H.W.; Zhang, J.M.; Wei, N.Q.; Huang, H. Stable oxygen isotope in precipitation in relation to the meteorological factors and the moisture sources in Yunnan. J. Nat. Resour. 2014, 29, 1043-1052. (In Chinese)

11. Wu, H.W.; Zhang, X.P.; Li, X.Y.; Li, G.; Huang, Y.M. Seasonal variations of deuterium and oxygen-18 isotopes and their response to moisture source for precipitation events in the subtropical monsoon region. Hydrol. Process. 2015, 29, 90-102. [CrossRef]

12. Dansgaard, W. Stable isotopes in precipitations. Tellus 1964, 16, 436-468. [CrossRef]

13. Xia, C.C.; Liu, G.D.; Mei, J.; Meng, Y.C.; Liu, W.; Hu, Y. Characteristics of hydrogen and oxygen stable isotopes in precipitation and the environmental controls in tropical monsoon climatic zone. Int. J. Hydrog. Energy 2019, 44, 5417-5427. [CrossRef]

14. Breitenbach, S.F.M.; Adkins, J.F.; Meyer, H.; Marwan, N.; Kumar, K.K.; Haug, G.H. Strong influence of water vapor source dynamics on stable isotopes in precipitation observed in Southern Meghalaya, NE India. Earth Planet. Sci. Lett. 2010, 292, 212-220. [CrossRef]

15. Kong, Y.L.; Wang, K.; Li, J.; Pang, Z.H. Stable Isotopes of Precipitation in China: A Consideration of Moisture Sources. Water 2019, 11, 1239. [CrossRef]

16. Stumpp, C.; Klaus, J.; Stichler, W. Analysis of long-term stable isotopic composition in German precipitation. J. Hydrol. 2014, 517, 351-361. [CrossRef]

17. Xie, L.H.; Wei, G.J.; Deng, W.F.; Zhao, X.L. Daily $\delta^{18} \mathrm{O}$ and $\delta \mathrm{D}$ of precipitations from 2007 to 2009 in Guangzhou, South China: Implications for changes of moisture sources. J. Hydrol. 2011, 400, 477-489. [CrossRef]

18. Xu, T.; Sun, X.S.; Hong, H.; Wang, X.Y.; Cui, M.Y.; Lei, G.L.; Gao, L.; Liu, J.; Mahjoor, A.L.; Jiang, X.Y. Stable isotope ratios of typhoon rains in Fuzhou, Southeast China, during 2013-2017. J. Hydrol. 2019, 570, 445-453. [CrossRef]

19. Li, J.; Tao, T.; Pang, Z.H.; Tan, M.; Kong, Y.L.; Duan, W.H.; Zhang, Y.W. Identification of different moisture sources through isotopic monitoring during a storm event. J. Hydrometeorol. 2015, 16, 1918-1927. [CrossRef]

20. Celle-Jeanton, H.; Gonfiantini, R.; Travi, Y.; Sol, B. Oxygen18 variations of rainwater during precipitation: Application of the Rayleigh model to selected rainfalls in southern France. J. Hydrol. 2004, 289, 165-177. [CrossRef]

21. Coplen, T.B.; Neiman, P.J.; White, A.B.; Landwehr, J.M.; Ralph, F.M.; Dettinger, M.D. Extreme changes in stable hydrogen isotopes and precipitation characteristics in a landfalling Pacific storm. Geophys. Res. Lett. 2008, 35, L21808. [CrossRef]

22. Barras, V.; Simmonds, I. Observation and modelling of stable water isotopes as diagnostics of rainfall dynamics over southeastern Australia. J. Geophys. Res. 2009, 114, 1-17. [CrossRef]

23. Miyake, Y. An isotopic study on meteoric precipitation. Pap. Meteorol. Geophys. 1968, 19, 243-266. [CrossRef]

24. Munksgaard, N.; Wurster, C.; Bass, A.; Bird, M. Extreme short term stable isotope variability revealed by continuous rainwater analysis. Hydrol. Process. 2012, 26, 3630-3634. [CrossRef]

25. Zhang, P.L. A Study of the Human-Environment Relationship in Lanzhou Basin Based on Topography. Master's Thesis, Lanzhou University, Lanzhou, China, 2017.

26. Yao, T.D.; Zhou, H.; Yang, X.X. Indian monsoon influences altitude effect of $\delta^{18} \mathrm{O}$ in precipitation/river water on the Tibetan Plateau. Chin. Sci. Bull. 2009, 54, 2724-2731. [CrossRef] 
27. Hu, J.Q.; Liu, W.F.; Chang, Z.M.; Zhang, J.X. Study on variation signal of precipitation in Lanzhou from 1951 to 2015. Water Res. Hydropower Eng. 2017, 48, 8-12.

28. Huff, F.A. Time distribution of rainfall in heavy storms. Water Resour. Res. 1967, 3, 1007-1019. [CrossRef]

29. Han, T.T.; Zhang, M.J.; Wang, S.J.; Du, Q.Q.; Ma, Z.Z.; Guo, R.; Cao, Y.F. Characteristics of stable isotopes and moisture sources of two typical precipitation events in Lanzhou. Environ. Sci. 2020, 9, 1-14. (In Chinese)

30. Benetti, M.; Reverdin, G.; Pierre, C.; Merlivat, L.; Risi, C.; Steen-Larsen, H.C.; Vimeux, F. Deuterium excess in marine water vapor: Dependency on relative humidity and surface wind speed during evaporation. J. Geophys. Res. 2014, 119, 584-593. [CrossRef]

31. Tian, C.; Wang, L.X. Stable isotope variations of daily precipitation from 2014-2018 in the central United States. Sci. Data 2019, 6, 190018. [CrossRef]

32. Gat, J.R. Atmospheric water balance-The isotopic perspective. Hydrol. Processes 2000, 14, 1357-1369. [CrossRef]

33. Trenberth, K.E. Atmospheric moisture residence times and cycling: Implications for rainfall rates and climate change. Clim. Chang. 1998, 39, 667-694. [CrossRef]

34. Gonfiantini, R.; Roche, M.; Olivry, J.; Fontes, J.; Zuppi, G.M. The altitude effect on the isotopic composition of tropical rains. Chem. Geol. 2001, 181, 147-167. [CrossRef]

35. Du, M.X.; Zhang, M.J.; Wang, S.J.; Chen, F.L.; Zhao, P.P.; Zhou, S.E.; Zhang, Y.N. Stable Isotope Ratios in Tap Water of a Riverside City in a Semi-Arid Climate: An Application to Water Source Determinatio. Water 2019, 11, 1441. [CrossRef]

36. Craig, H. Isotopic variations in meteoric waters. Science 1961, 133, 1702-1703. [CrossRef] [PubMed]

37. Chen, F.L.; Zhang, M.J.; Ma, Q.; Li, X.F.; Wang, S.J.; Li, F. Characteristics of $\delta^{18} \mathrm{O}$ in precipitation and water vapor sources in Lanzhou city and its surrounding area. Environ. Sci. 2013, 34, 3755-3763. (In Chinese)

38. He, S.N.; Goodkin, N.F.; Kurita, N.; Wang, X.F.; Rubin, C.M. Stable isotopes of precipitation during tropical Sumatra squalls in Singapore. Geophys. Res. 2018, 123, 3812-3829. [CrossRef]

39. Lee, J.E.; Fung, I. "Amount effect" of water isotopes and quantitative analysis of post-condensation processes. Hydrol. Process. 2008, 22, 1-8. [CrossRef]

40. Ma, Q.; Zhang, M.J.; Wang, S.J.; Wang, B.L. Contributions of moisture from local evaporation to precipitations in Southeast China based on hydrogen and oxygen isotopes. Prog. Geography. 2013, 32, 1712-1720. (In Chinese)

41. Zhang, M.J.; Wang, S.J. A review of precipitation isotope studies in China: Basic pattern and hydrological process. J. Geogr. Sci. 2016, 26, 921-938. [CrossRef]

42. Sun, C.J.; Chen, Y.N.; Li, J.; Chen, W.; Li, X.G. Stable isotope variations in precipitation in the northwestern most Tibetan Plateau related to various meteorological controlling factors. Atmos. Res. 2019, 227, 66-78. [CrossRef]

43. Li, Z.X.; Feng, Q.; Yong, S.; Wang, Q.J.; Jiao, Y.; Li, Y.G.; Li, J.G.; Guo, X.Y. Stable isotope composition of precipitation in the south and north slopes of Wushaoling Mountain, northwestern China. Atmos. Res. 2016, 182, 87-101. [CrossRef]

44. Adar, E.M.; Karnieli, A.; Sandler, B.Z.; Issar, A.; Wolf, M.; Landsman, L. A Mechanical Sequential Rain Sampler for Isotopic and Chemical Analyses; Final Scientific Report, contract no. 5542/RO/Rb; IAEA: Vienna, Austria, 1991.

45. Muller, C.L.; Baker, A.; Fairchild, I.J.; Kidd, C.; Boomer, I. Intra-event trends in stable isotopes: Exploring midlatitude precipitation using a vertically pointing micro rain radar. J. Hydrometeorol. 2015, 16, 194-213. [CrossRef]

46. Stewart, M.K. Stable isotope fractionation due to evaporation and isotopic exchange of falling waterdrops: Applications to atmospheric processes and evaporation of lakes. J. Geophys. Res. 1975, 80, 1133-1146. [CrossRef]

47. Gat, J.R.; Bowser, C.J.; Kendall, C. The contribution of evaporation from the Great Lakes to the continental atmosphere: Estimate based on stable isotope data. Geophys. Res. Lett. 1994, 21, 557-560. [CrossRef]

48. Huang, W.; Chen, J.H.; Zhang, X.J.; Feng, S.; Chen, F.H. Definition of the core zone of the "westerlies-dominated climatic regime", and its controlling factors during the instrumental period. Sci. China Earth Sci. 2015, 58, 676-684. [CrossRef]

(C) 2020 by the authors. Licensee MDPI, Basel, Switzerland. This article is an open access article distributed under the terms and conditions of the Creative Commons Attribution (CC BY) license (http://creativecommons.org/licenses/by/4.0/). 